\title{
COMMENT
}

\section{Challenges of academic pediatric medicine: the American Pediatric Society and Society for Pediatric Research Virtual Chat Series}

\author{
Steven H. Abman (D) ${ }^{1}$ and Stephanie D. Davis ${ }^{2}$ \\ Pediatric Research (2022) 91:1320-1321; https://doi.org/10.1038/s41390-020-01165-z
}

As the SARS-CoV-2 pandemic led to the cancellation of major scientific meetings throughout the world this past Spring, the Pediatric Academic Society (PAS) meeting suffered a similar fate. Given this, we missed seeing each other for both professional and social purposes. Most importantly, we lost the opportunity to present and discuss the outstanding cutting-edge science from trainees, faculty, and others, along with the many thematic seminars, workshops, and symposia that represent the broad scope of pediatric research.

We also missed the opportunity to discuss many timely and critical issues related to academic pediatrics beyond the excellent science presented at PAS, such as themes regarding different challenges of enhancing career development, diversity, equity, inclusion, and racism issues within academic medicine, establishing research programs, addressing collaborations within the era of team science, balancing clinical and research demands, navigating career choices throughout an academic lifespan, and many difficult issues facing modern departments and health science centers.

To address these many challenges facing academic pediatrics, the American Pediatric Society (APS) and Society for Pediatric Research (SPR) have jointly created a series of virtual thematic meetings and discussions presented by leaders from our societies and others. The APS and SPR organized a 10 part series. The overall goal of this webinar series is to present timely and vital issues regarding academic pediatrics as provided by outstanding and diverse leaders, including prominent faculty leaders, medical school deans, department chairs and vice-chairs, section chiefs, heads of research institutes and academic training programs, and other academic leaders. The participating faculty have diverse backgrounds and experiences, which provide exceptional and highly impactful guidance to many aspects of our field, including research, training, advocacy, clinical care, and leadership.

The structure of these webinars includes brief presentations from our experts followed by moderated but informal discussions "by chat" among the participants. The specific topics of the "APS/ SPR Virtual Chats" series include: attracting and retaining successful careers from the early, mid-level and senior stages; achieving diversity and equity and inclusion in academic medicine; addressing social disparities that impact child health; balancing academic and economic issues in academic medical centers; enhancing mentor-mentee relationships; understanding the dynamics, functions, and opportunities within sections and departments; strategies to improve grant funding and publication success; and developing successful careers and leadership in advocacy.

While limited by plans to keep each session between 60 and 90 min, this series provides an opportunity for participants to learn not only from the speakers, but also from each other through these moderated discussions. Each session can be joined during live presentation and will also be recorded and made available for viewing through repositories on the APS and SPR websites (https://www.aps1888.org/aps-spr-virtual-chats).

We believe that this series will provide unique opportunities for early-career, mid-level, and senior academicians with diverse backgrounds and primary interests to share insights into vital issues that currently challenge our ability to improve child health outcomes through our missions of research, education, training, clinical care, and advocacy. We hope that these sessions will provide new insights into current barriers or gaps in academic medicine, novel strategies to overcome these hurdles, and will stimulate new thinking in each of these areas.

\begin{tabular}{|c|c|}
\hline \multicolumn{2}{|l|}{ Schedule: } \\
\hline Date & Topics \\
\hline une 22 & $\begin{array}{l}\text { "Transitions: Navigating Career Choices throughout the } \\
\text { Lifespan" }\end{array}$ \\
\hline July 20 & "Disparities in Child Health Care and Outcome" \\
\hline lugust 24 & $\begin{array}{l}\text { "Challenges facing Academic Medicine in the Modern Era: } \\
\text { The Deans' View" }\end{array}$ \\
\hline eptember 21 & "Valuing and Achieving Diversity in Academic Medicine" \\
\hline October 19 & $\begin{array}{l}\text { "Insights into the Impact of Sections and Departments on } \\
\text { Your Career" }\end{array}$ \\
\hline November 16 & “Mentor-Mentee Interactions: A 2-Way Street” \\
\hline December 21 & "Academic Skills: Of Grants and Publications" \\
\hline January 25 & "Enhancing Academic Careers throughout the Pipeline" \\
\hline February 22 & $\begin{array}{l}\text { "Developing Careers and Strategies to Promote Advocacy } \\
\text { in Child Health" }\end{array}$ \\
\hline March 22 & $\begin{array}{l}\text { "Aligning Academic Medicine within the Healthcare } \\
\text { System" }\end{array}$ \\
\hline
\end{tabular}

${ }^{1}$ Department of Pediatrics, University of Colorado Anschutz School of Medicine and Children's Hospital Colorado, Aurora, CO, USA and ${ }^{2}$ Department of Pediatrics, University of North Carolina School of Medicine, Chapel Hill, NC, USA

Correspondence: Steven H. Abman (steven.abman@cuanschutz.edu)

Received: 13 July 2020 Revised: 20 July 2020 Accepted: 4 August 2020

Published online: 17 September 2020 
Challenges of academic pediatric medicine: the American Pediatric Society... SH Abman and SD Davis

ACKNOWLEDGEMENTS

We are grateful for the outstanding support of the APS and SPR staffs, including Michelle Brunoehler, Jaimee Chumley, Jana Wells, Eileen Fenton, and Shelley Jobe.

\section{ADDITIONAL INFORMATION}

Competing interests: The authors declare no competing interests.

Publisher's note Springer Nature remains neutral with regard to jurisdictional claims in published maps and institutional affiliations. 